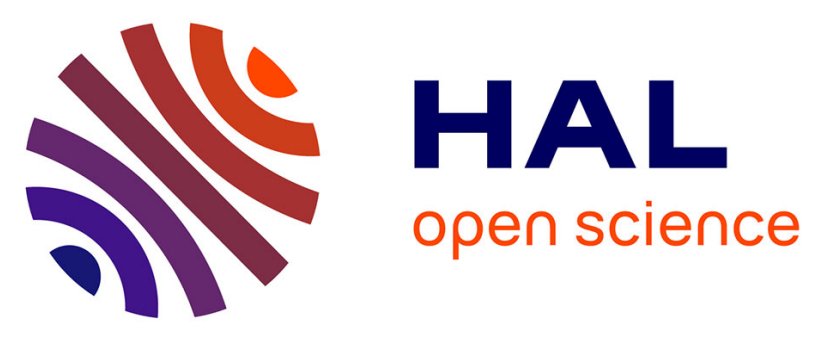

\title{
Product Lifecycle Management Strategy for the Definition and Design Process of Face Implants Oriented to Specific Patients
}

Cristian C. Ardila-Mejia, Clara Isabel Isabel López Gualdrón, Javier Mauricio Mauricio Martínez Gómez

\section{To cite this version:}

Cristian C. Ardila-Mejia, Clara Isabel Isabel López Gualdrón, Javier Mauricio Mauricio Martínez Gómez. Product Lifecycle Management Strategy for the Definition and Design Process of Face Implants Oriented to Specific Patients. 15th IFIP International Conference on Product Lifecycle Management (PLM), Jul 2018, Turin, Italy. pp.181-190, 10.1007/978-3-030-01614-2_17 . hal-02075632

\section{HAL Id: hal-02075632 \\ https://hal.inria.fr/hal-02075632}

Submitted on 21 Mar 2019

HAL is a multi-disciplinary open access archive for the deposit and dissemination of scientific research documents, whether they are published or not. The documents may come from teaching and research institutions in France or abroad, or from public or private research centers.
L'archive ouverte pluridisciplinaire HAL, est destinée au dépôt et à la diffusion de documents scientifiques de niveau recherche, publiés ou non, émanant des établissements d'enseignement et de recherche français ou étrangers, des laboratoires publics ou privés.

\section{(c)(1)}

Distributed under a Creative Commons Attribution| 4.0 International License 


\title{
Product Lifecycle Management strategy for the definition and design process of face implants oriented to specific patients
}

\author{
Cristian C. Ardila-Mejía; Clara Isabel López-Gualdrón; Martínez Gómez, Javier \\ Mauricio $^{3}$ \\ ${ }^{1}$ Industrial designer; Universidad Industrial de Santander, Santander, Colombia. \\ cristianc.am9310@gmail.com \\ ${ }^{2} \mathrm{PhD}(\mathrm{c})$ Engineering technology management; Universidad Industrial de Santander, Santander, \\ Colombia. \\ clalogueuis.edu.co \\ ${ }^{3} \mathrm{PhD}$ Sistemi di Produzione\&DesignIndustriale; Universidad Industrial de Santander, Santan- \\ der, Colombia. \\ javimar@uis.edu.co
}

\begin{abstract}
The main purpose of this research was oriented to generate a structured modelfrom an organizational vision to the definition and development of precise osteosynthesis prosthesis. Implants were adapted to the Colombian population anthropometry allowing fracture reductions and craniofacial defects corrections based on technologies for specific patients. This research was developed taking into account the first three PLM stages: Imagination, definition, and realization. Procedures, stages, roles, and activities that take part in the design and pre-surgical planning were identified for the patient-specific implants PSI,carried out through a study case. It was established as a definition model for design and fabrication process of patient-specific implants (PSI).It was possible that technology included in a collaborative workflow wherein the roles which intervene in the design process and the pre-surgical planning were related. The abilityto design implants for specific patients and surgical guides was obtained different pathology situations including face trauma.According to the PLM strategy for designingcustom implant, it would be possible to buildinnovation capabilities. With those, an organization could generate a collaborative workflow integrating stages, roles, activities, applying technology and local human resource. Further work related to the subject is necessary to enhancethe process by iteration and improve the clinical cases management.
\end{abstract}

Keywords:Collaborative workflow; digital manufacturing; patient-specific device; PLM model; virtual surgical planning.

adfa, p. 1, 2011.

(C) Springer-Verlag Berlin Heidelberg 2011 


\section{Introduction}

Development of new medical devices influences strongly in the surgical quality, that increases a better anatomical situation, real quantity of bone, and reconstruction demands. Therefore,functional restorationis achieved through those devices[1]. From those is obtained a surer, shorter and timepredictable surgery[2].

Nowadays, plastic surgery is the health specialty with more influence in the reconstructive field for patients with osseous craniofacial defects[3], [4].Surgeons have found complex defects that have been corrected through medical devices such as surgical guides and patient-specific implants (PSI). These devices, also known as patientspecific devices (PSD), are designed according to the patient osseous structure and allowing restoration of anatomical appearance looking for aesthetic and functional properties[3]. However,virtual technologyand digital manufacturing make possible application, which isnecessary to medical procedures, such as diagnosis, pre-surgical planning, andsurgery, becomingless complex by reducing uncertainty [5].

The main four steps in PSI development are: First, making a digital reconstruction model. Second, design process and device simulation. Third, evaluatethe accuracy of the PSI compared with the biological surface. Fourth, piece evaluation[2]. The development of those steps in the process of PSI deviceinvolve tools such asreverse engineering (RE), computer-aideddesign - manufacturing- engineering (CAx), 3D modeling, and rapid prototyping (RP) techniques[6], [7].

Although the importance of the virtual technologies to guarantee PSI development, there would beuncertainty in the development process of this product related to its application on surgery. Implant design process is complex.To achieve medicalrequirementit demands lots of time and effort. That is why a specialized staff is mandatory, as well a complete evaluation of skull condition, soft tissue bundle, greater accuracy, and time during trauma treatment[1], [2].The use of specialized software allows reducing the vagueness in precision and accuracy[5]. This implies thata multidisciplinary team must articulate different profiles in the organized structured way insidea collaborative workflow,defining roles and activities atPSI development.

PLM strategy has been implemented successfully in the automotive and aerospace industry[7]. They have defined anintegrative vision of PLM strategy, that led to optimizing development time and resources, reducingmistakes on design and manufacture stages, increasing productivity and change controlling[8].Product Lifecycle Management (PLM) has been set to control RE procedures, to take geometric or organic models as input. RE is been applying in the design process due to its feature to bring human models and the instance ofusing CAx tools to modify components [8], [9]. PLMstrategy involves product data management PDM software, aninformation technology resource that enables a company to structure a collaborative workflow in safety database. It is useful to planning resources and creating a communication path among different stages, like design, manufacture, sales, support, and elimination.Its value resides in controlprocedures and selects the accurate tools to intervene through lifecycle product[9], [10]. Quality control and traceability of the process are crucial for medical device, topics which could be covered by PLM implemented strategy[11], [12].This research defines the application of a PLM strategylooking for improving the 
development process of medical devices in a public university hospital from a developing country.The main contribution of this paper is related to the proposal of a visual model for PLM strategy in a non-traditional field such as Health. This paper wasstructured into four parts:first,materials and methods. Second, a PLM strategies structure proposed. Third, a case report is presented. Fourth, the conclusion of PLM implementation related to study case.

\section{$2 \quad$ Materials and methods}

This research was developed in the following way: Thefirst stage was to understandthe current situation. This stage was divided in two: first, an exploratory study was conducted todefining procedures for PSI development in a Public University Hospital. Field observation was executed in the subject of context through collecting data about people, artifacts,and procedures, with non-structured interviews. Data were organized according to the timeline for patient attention, specifically on maxillofacial surgery field. Second, a non-structured literature review was conducted, related with PSI for skull and face recovery cases, in order to identify software tools for imaging, virtual reconstruction, modeling and 3D printing of custom medical devices.The second stage was toproposea process line withinthe public university hospital for developinga PSI, by implementing a PLM strategytomake decision process and pre-surgical planning. In order to meet this objective, current sequential flow from user perspective was first identified. Then, process areas were established according to fundamental activities from diagnosis, to design, and manufacture. Then, it was analyzed how the proposed PLM strategy could be according with a process toobtaining a PSI. Once workflow and software tools were defined, PLM strategies through project data management (PDM) were applied.

Finally, in the third stage, according to previous evaluation, a new workflow was proposed according to PLM strategies, in order to get a design process for craniofacial implants. For verification purposes, the new workflow was applied to onestudy case. The evaluation scope was to confirmingthe design solutions proposed. The accuracy of PSI was verified by physician concept. With that in mind, activities for implant development in the case study were integratedthrough a PDM.

\section{$3 \quad$ PLM strategy structuration results.}

A strategy based on product lifecycle was proposed to define craniofacial implants design from current workflow patient service, which showed opportunities to improve the service. Implementation of a visual model allows forcontrolling productivity associatedwith equipment, according to each stage involved in the development of the product. This model provides transparency from a Top-down approach[13].

To establish a PLM strategy visual framework,main stages were specified. From academic scope, covered lifecyclejust include the initial three: imagination, definition, and realization. Then, process areas involved in main stages were identified:requirements, design, manufacturing, testing, and knowledge management. Each 
one has a workflow that connects among others, through every activity performed by a specific role. Thought decomposition graphics in every activity, a role is understanding, as well as its skills, tools, and input or output items. [13]

\subsection{Current process description:}

Through observation techniques and non-structured interviews, the process related to surgical treatment was drawn. A business process model BMP was made to get a graphic flow that showed activities in the timeline when a patient asks for health attention. It is established that in complex craniofacial trauma cases, use of PSI implants is applied where standard implants performance would be no adequate, although in many cases the surgeon had no other choices. Figure 1 shows an opportunity to include design area in pre-surgical planning procedure. That would enhance endogenous advance of PED under a service procedure based on PLM strategy that facilitates collaboration among multidisciplinary roles.

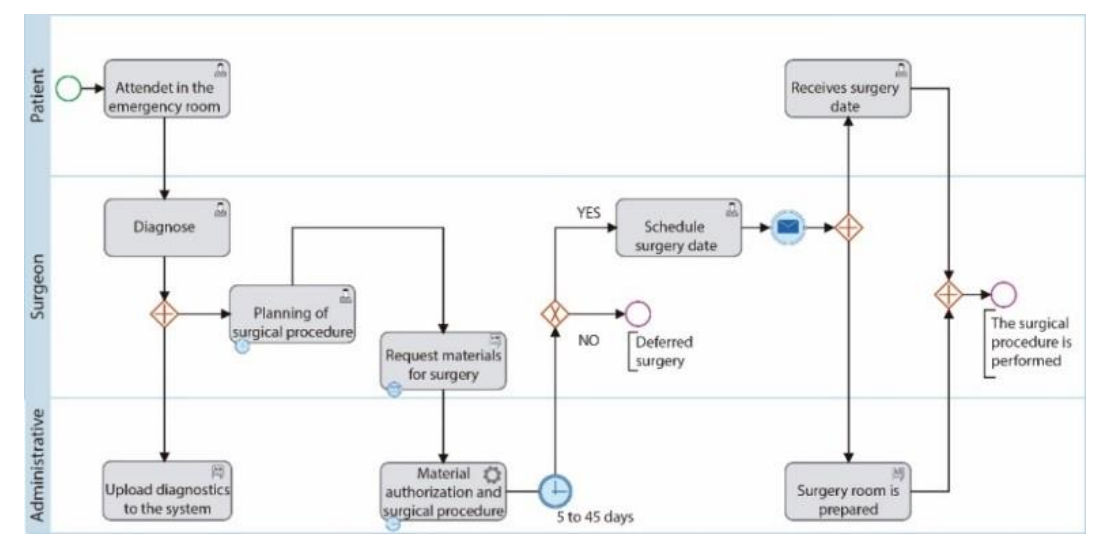

Fig. 1.Workflow in the Hospital. Sequential process observed by authors.

\subsection{Building a visual model. Stage/ areas description:}

Activities involved in the process ofobtaining a PSI implantmust match by correspondence. Related works in literature are focused on digital workflow in reconstructive implants [15], and how to share complex and heavy data from imaging [16], [17]. A few works presented exchange problems between roles in health [18], specifically how people must conduct a PLM implementation according to organization objectives would be a lack[19]. That gap was identified in the literature review, and next, it was proposed a PLM strategy in order to adapt it to a public university hospital.

The process areas framed in the initial three stages of the PLM approach suggested by Starkwere adopted, which correspond to the stages of imagination, definition, and realization[20] as shown in figure 2 . That also corresponds with the research scope, in order to reduce complexity on technical data management [21]. 
First, imagination stage.Diagnosis and analysisarea has to get information about the patient situation. In this process area, a specialist identifies a defect. Specialist generates a list of requirements that a specific device must accomplish for the patient.Second, definition stage. Three process areas interact as following: first, 3D reconstruction process area, the one in charge to translateDigital Imaging and Communications in Medicine DICOM images[22] from tomography to a 3D biomodel by means of RE technologies[23]. Second, the design area, where the PSI should be virtually made following specifications ispreviouslygiven by the specialist[24]. Third, knowledge management, where practices related to acquiring information for current and future products are established.Third, realizationstage. Rapid prototyping processes areestablished, rather a biomodel, a PSI, or a surgical guide would be needed, according toany case. Validation must perform by testing quality, or metrology process area, where the evaluation, measurement, and verification of product quality are carried out. Knowledge management area acts again, to creating information manuals for the production process and user manualsfor PED. See Figure 2.

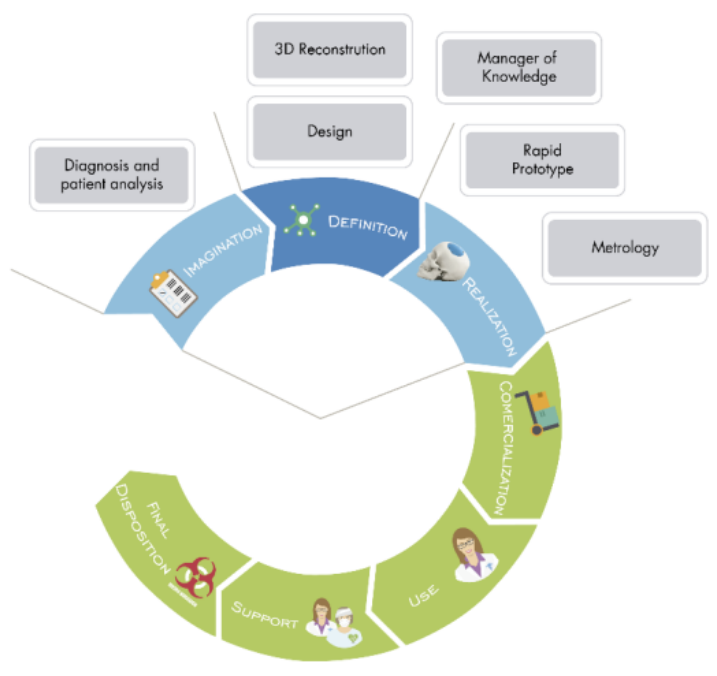

Fig. 2.The initial stage of Lifecycle and Process areas involved, proposed by authors.

\subsection{Roles and technology integration:}

Once the process area was established, roles that are involved in PSI development procedures were identified with his respective technological tools. These roleswere integrated by a public access PDM. Selection from PLM services are complex and deepens of organization resources[13]. Due economic limitation, a public PDMservice was selected, the GrabCAD workbench from Stratasys [25]. That tool allowsinteraction among different roles, being possible to visualize change estates on $3 \mathrm{D}$ files.Although a role could be performed at least by one person, roles definition corresponds to: 
- Surgeon specialist: Who generates requirements from the patient about a product and asks the designer for a service according to needs. He is an expert on the surgical correction that requires repair or replacesa craniofacial bone structure.

- Requirements analyst: Whodirects requirements process area. That role coordinates to obtaining requirements fromthe indirect user (the surgeon) todefine product functionality. Analyst deployed activities in PDM,looking for controlling requirementto accomplishing or updating in every process areas.

- Reverse Engineer: Who carries out the translation from DICOM to 3D reconstruction. A trained person who domains reverse engineering techniques.

- Designer: The designer role is responsible for the design process according to the needs and requirements requested. He must have knowledge regarding creativity, innovation and design, computational skills in software creation PSI products.

- Rapid Prototyping Operator:The one who performs 3D printing according to the indications given by manufacture requirements.

- Knowledge manager: Consists of identifying, collecting, managing and storing the knowledge, so that this can be shared, reviewed, and modified in a safety way.

- Metrology Engineer: Who carries out the inspections and product verifications. He finally evaluates manufacturing costs from other areas.

\subsection{Medical Prosthesis Development. A proposed workflow}

Three study cases with craniofacial defects were done. The cases need to be attended by a physician specialist.The main target was to know the common activities to develop each case. Then, a collaborative workflow was performed where roles that intervene in a PSD design interact constantly along the whole procedure.Next, study cases related to PSD(pre-surgical planning, surgical guides, andPSI) was shown.In figure 3, a workflow for PSI development wassuggested. Procedureswere according to activities and steps in a public hospital,whichwas taken as reference. Those activities flow through different professionals, whom could accept or rejectinputs and outputs form each activity, taking into account custom conditions for each device. Proposed workflow is described as follows:

First, the surgeon specialist SS identifies the defect that should be treated. Specialist generates a diagnosis and requests a service based on the cost analysis and justification about advantages. In this stage, procedure requested is assessed by requirements analyst, is appropriate or not for the patient. The PS probably requests the service in an iterative way until all changes suggested over the first proposal were defined, including overall schedule and a probable price.

Once the proposal is accepted, reverse engineer intervenes, getting TAC images from Hospital, traducing DICOM to a virtual 3D shape, and correcting mesh. Next, designer structures all ideas to be developed using $3 \mathrm{D}$ imaging as input. When the designer has already done a concept, PS intervenes again in establishing if concept accomplishes expectations or must be modified. Once SS concedes his approval, detailing design, materialization and refinement are carried out. At this point, idea evolves to the product, and designer recommends specifications for each device. It is verified whether rapid prototyping could be done or it must be configured from con- 
cept refinement again. With a final design, metrology engineer ME could evaluate the performance virtually or physically by testing. If ME approves, knowledge manager could create a product manual for the application, bringing a compact product to SS.

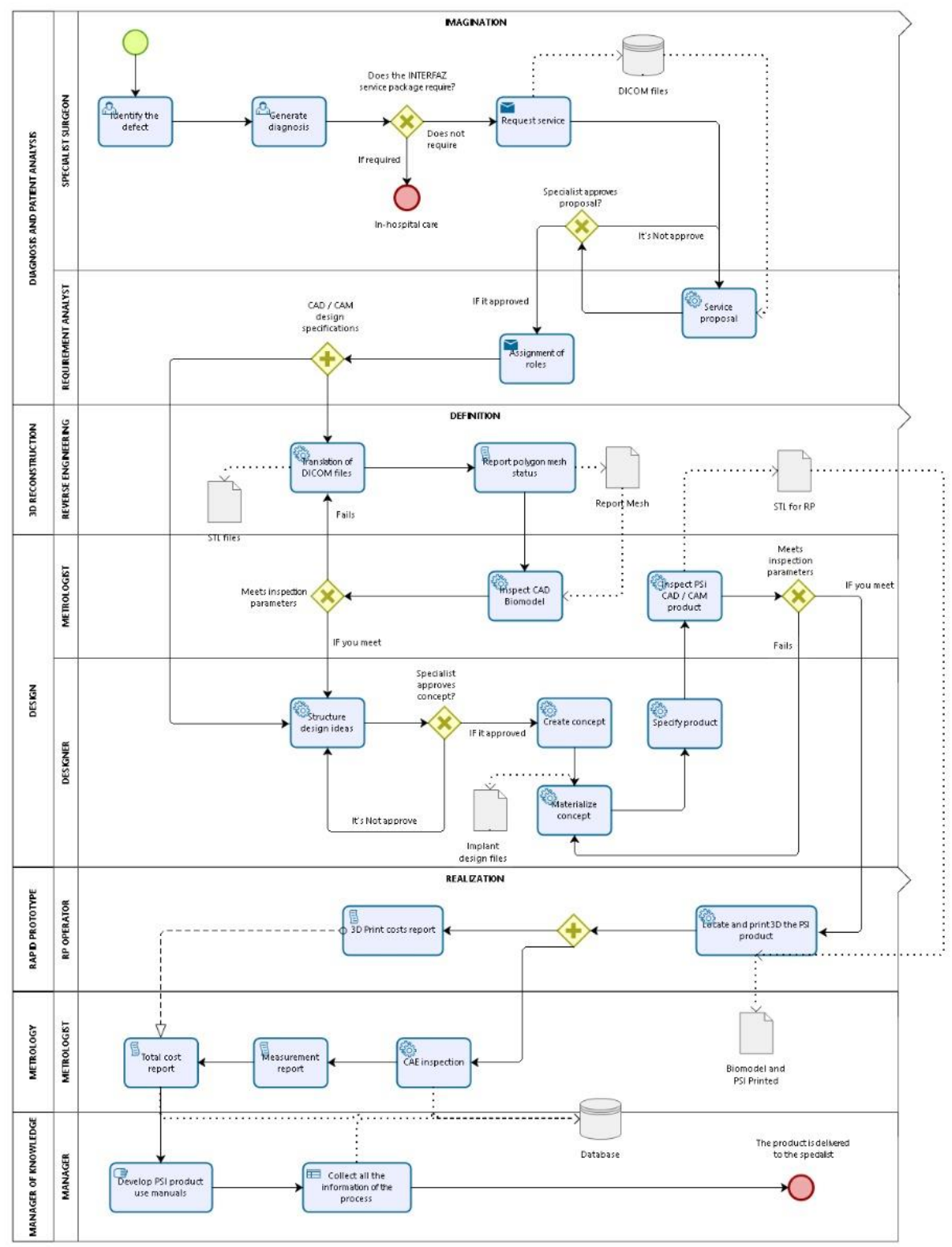

Fig.3.Systematic Workflow proposed by authors. 


\section{Study case.}

The collaborative workflow was proposed andimplemented for a study case. The patient was diagnosed with sequels Le-fort 1 of cleft palate with retrusion of congenital type maxilla, see figure 4 . The surgeon specialist requests the design of a cutting guide for osteosynthesis, and the pre-surgical planning to improve the patient's bite.
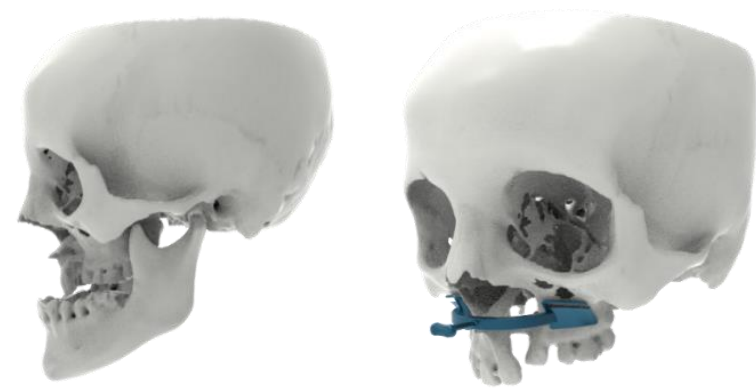

Fig. 4. Study case. Image drawn by authors.

Roles communication and technology integration were taken into account. Table 1 shows time spent in each stage according to activity. Comparing with other works [26], time reduction must be a goal for future developments.

Table 1. Time for each activity

\begin{tabular}{|l|l|c|}
\hline STAGE & Activities & TIME $(\mathrm{h})$ \\
\hline \multirow{4}{*}{ IMAGINATION } & Defect identification / Diagnosis generation & 8 \\
\cline { 2 - 3 } & Requesting service & 0.5 \\
\cline { 2 - 3 } & Requirements management & 3 \\
\hline \multirow{5}{*}{ DEFINITION } & Roles assignation & 1.5 \\
\cline { 2 - 3 } & Reverse engineering & 8 \\
\cline { 2 - 3 } & Mesh correction & 8 \\
\cline { 2 - 3 } & Ideas structuration & 5 \\
\cline { 2 - 3 } & Concept creation & 14 \\
\cline { 2 - 3 } & Concept evaluation & 4 \\
\cline { 2 - 3 } & Concept materialization & 1 \\
\cline { 2 - 3 } & Product specification & 0.5 \\
\cline { 2 - 3 } & Measure verification & 2 \\
\hline \multirow{5}{*}{ REALIZATION } & Rapid prototyping & 2 \\
\cline { 2 - 3 } & Knowledge management & 2.7 \\
\cline { 2 - 3 } & Information manuals generation & \\
\hline
\end{tabular}


Finally, a prototype was brought to surgery to check, according to surgeon specialist observation, if it fits osseous geometry or not.Thatcutting guide was not usedalong the surgicalprocedure. It was sterilized and its contact was less than 10 seconds. Integration of RE, CAx, and RP technologies was established, founding guidelines and proceduresto development. Co-creation among key roles and technological tools were also defined.Technology inclusion was possible within a collaborative workflow where roles are constantly interacting. The capability to generate PED must beobtained by experience by attending different situations of pathology treatment.

\section{Conclusions}

Based on the PLM strategy for the design of the patient-specific implant it is possible to buildcapabilities to generate a collaborative workflow integrating stages, roles, activities and a workflow with technology and local human resource. PLM strategy improves the development of the case in an organized manner allowing to knowledge management. However, it is necessary to implement cost validation and control scheduling in activities, in order to measure biomodel results, starting with academic validation.Developing PDM software could be recommended to improve roles interaction and interface, easing exchange formats requested for each case.Develop the four remaining stages of the PLM strategy(commercialization, use, support, and disposal) will implyfurther research and effort, todevelop stages which were not taken into account on this paperreducing complexity and because that would be beyond research scope.

\section{$6 \quad$ References}

[1] S. Hassfeld and J. Mühling, "Computer assisted oral and maxillofacial surgery - A review and an assessment of technology," Int. J. Oral Maxillofac. Surg., vol. 30, no. 1, pp. 2-13, 2001.

[2] J. Zhang et al., "Customized titanium mesh for repairing cranial defects: A method with comprehensive evaluation," J. Craniofac. Surg., vol. 26, no. 8, pp. e758-e761, 2015.

[3] A. García, M. Á. Morey, M. Ramos, S. Janeiro, I. Molina, and J. I. Iriarte, "Reconstrucción de la articulación temporomandibular postraumática con prótesis a medida. Planificación quirúrgica virtual," Rev. Esp. Cir. Oral y Maxilofac., vol. 33, no. 2, pp. 53-60, 2011.

[4] M. González de Santiago, L. Chaurand, and B. Sandoval, "Cranial reconstruction with a custom-made implant," Rev Esp Cir Oral Maxilofac, vol. 3333, no. 1, pp. 40-44, 2011.

[5] F. Rengier et al., "3D printing based on imaging data: Review of medical applications," Int. J. Comput. Assist. Radiol. Surg., vol. 5, no. 4, pp. 335-341, 2010.

[6] B. T. Goh and K. H. Teoh, "Orbital implant placement using a computeraided design and manufacturing (CAD/CAM) stereolithographic surgical 
template protocol,” Int. J. Oral Maxillofac. Surg., vol. 44, no. 5, pp. 642-648, 2015.

[7] M. W. Grieves and M. Tanniru, "PLM, process, practice and provenance: knowledge provenance in support of business practices in Product Lifecycle Management," Int. J. Prod. Lifecycle Manag., vol. 3, no. 1, p. 37, 2008.

[8] A. Saaksvuori and A. Immonen, Product Lifecycle Management, Third Edit. Helsinki, Finland, 2008.

[9] F. Segonds, N. Maranzana, P. Veron, and A. Aoussat, "Collaborative Reverse Engineering Design Experiment Using PLM Solutions," Int. J. Eng. Educ., vol. 27, no. 5, pp. 1037-1045, 2012.

[10] J. Martínez, J. Sauza, F. Ricci, and P. Chiabert, "Validation process model for product lifecycle management," Int. J. Prod. Lifecycle Manag., vol. 7, no. 2/3, p. 230, 2014.

[11] F. Scott, W. Mcdonnell, and M. Burkett, "Designing Medical Devices To Improve Patient Outcomes," 2011.

[12] A. D. Lantada and P. L. Morgado, "Introduction to Modern Product Development," in Handbook on Advanced Design and Manufacturing Technologies for Biomedical Devices, Springer International, 2013, pp. 1-17.

[13] J. Martínez, "Visualization Model for Product Lifecycle Management: Processes, activities, roles and items involved in product lifecycle," Politecnico di Torino, 2013.

[14] J. M. Martínez, "Visualization Model for Product Lifecycle Management: Processes, activities, roles and items involved in product lifecycle," Politecnico di Torino, 2013.

[15] A. Unkovskiy, S. Spintzyk, J. Brom, F. Huettig, and C. Keutel, "Direct 3D printing of silicone facial prostheses: A preliminary experience in digital workflow," J. Prosthet. Dent., pp. 1-6, 2018.

[16] C. C. Pham et al., "How to share complex data and knowledge: Application in Bio-Imaging," IFAC-PapersOnLine, vol. 49, no. 12, pp. 1098-1103, 2016.

[17] M. Allanic, P.-Y. Hervé, A. Durupt, M. Joliot, P. Boutinaud, and B. Eynard, "PLM as a strategy for the management of heterogeneous information in BioMedical Imaging field," Int. J. Inf. Technol. Manag., vol. in press, no. 1, pp. 5-30, 2015.

[18] T. Ngo, A. Bernard, and F. Belkadi, "Interest of PLM for data sharing in the patient treatment process requiring prosthesis implantation," in $15 e$ Colloque National AIP-Priméca, 2017, no. 73, pp. 1-6.

[19] G. Schuh, H. Rozenfeld, D. Assmus, and E. Zancul, "Process oriented framework to support PLM implementation," Comput. Ind., vol. 59, no. 2-3, pp. 210-218, 2008.

[20] J. Stark, Product Lifecycle Management, Third Edit., vol. 2, no. Volume 2. Geneva, Switzerland: Springer International, 2016.

[21] O. Labbi, L. Ouzizi, M. Douimi, and Y. Aoura, "A Model to design a Product and its Extended Supply Chain integrating PLM (Product Lifecycle Management) Solution," Int. J. Sci. Eng. Res., vol. 7, no. 10, pp. 1190-1205, 2016. 
[22] T. R. Kucklick, The Medical Device R\&D Handbook, vol. 21. 2005.

[23] A. L. Jardini et al., "Cranial reconstruction: 3D biomodel and custom-built implant created using additive manufacturing," J. Cranio-Maxillofacial Surg., vol. 42, no. 8, pp. 1877-1884, 2014.

[24] G. A. Aitchison, D. W. L. Hukins, J. J. Parry, D. E. T. Shepherd, and S. G. Trotman, "A Review of the Design Process for Implantable Orthopedic Medical Devices,” Open Biomed. Eng. J., vol. 3, no. 1, pp. 21-27, 2009.

[25] D. Wu, J. Terpenny, and D. Schaefer, "Digital design and manufacturing on the cloud: A review of software and services," Artif. Intell. Eng. Des. Anal. Manuf., vol. 31, no. 1, pp. 104-118, 2017.

[26] T. Numajiri, H. Nakamura, Y. Sowa, and K. Nishino, "Low-cost Design and Manufacturing of Surgical Guides for Mandibular Reconstruction Using a Fibula," Plast. Reconstr. Surg. - Glob. Open, vol. 4, no. 7, p. e805, 2016. 